\title{
Association between polymorphisms in the aryl hydrocarbon receptor repressor gene and disseminated testicular germ cell cancer
}

\section{Leon J. S. Brokken ${ }^{1}$ *, Yvonne Lundberg-Giwercman ${ }^{1}$, Ewa Rajpert-De Meyts ${ }^{2}$, Jakob Eberhard ${ }^{3}$, Olof StåhI $^{3}$, Gabriella Cohn-Cedermark ${ }^{4}$, Gedske Daugaard ${ }^{5}$, Stefan Arver ${ }^{6}$ and Aleksander Giwercman ${ }^{1,7}$}

\author{
' Department of Molecular Reproductive Medicine, Lund University, Malmö, Sweden \\ ${ }^{2}$ Department of Growth and Reproduction, Rigshospitalet, Copenhagen, Denmark \\ ${ }^{3}$ Department of Oncology, Skåne University Hospital, Lund, Sweden \\ ${ }^{4}$ Department of Oncology-Pathology, Radiumhemmet, Karolinska Institute and University Hospital, Stockholm, Sweden \\ ${ }^{5}$ Department of Oncology, Rigshospitalet, Copenhagen, Denmark \\ ${ }^{6}$ Centre for Andrology and Sexual Medicine, Karolinska University Hospital Huddinge, Department of Medicine, Stockholm, Sweden \\ ${ }^{7}$ Reproductive Medicine Centre, Skåne University Hospital, Malmö, Sweden
}

\section{Edited by:}

Alberto Ferlin, University of Padova, Italy

\section{Reviewed by:}

Alessandra Mosca, University Hospital "Maggiore della Carità," Italy Loredana Gandini, University of Rome La Sapienza, Italy

\section{*Correspondence:}

Leon J. S. Brokken, Molecular Reproductive Medicine, Clinical Research Centre, Lund University, House 91, Floor 10, Jan Waldenströms gata 35, 20502 Malmö, Sweden.

e-mail: leon.brokken@med.lu.se
In the Western world, testicular germ cell cancer (TGCC) is the most common malignancy of young men. The malignant transformation of germ cells is thought to be caused by developmental and hormonal disturbances, probably related to environmental and lifestyle factors because of rapidly increasing incidence of TGCC in some countries. Additionally, there is a strong genetic component that affects susceptibility. However, genetic polymorphisms that have been identified so far only partially explain the risk of TGCC. Many of the persistent environmental pollutants act through the aryl hydrocarbon receptor (AHR). AHR signaling pathway is known to interfere with reproductive hormone signaling, which is supposed to play a role in the pathogenesis and invasive progression of TGCC. The aim of the present study was to identify whether AHR-related polymorphisms were associated with risk as well as histological and clinical features of TGCC in 367 patients and 537 controls. Haplotype-tagging single-nucleotide polymorphisms (SNPs) were genotyped in genes encoding AHR and AHR repressor (AHRR). Binary logistic regression was used to calculate the risk of TGCC, non-seminoma versus seminoma, and metastasis versus localized disease. Four SNPs in AHRR demonstrated a significant allele association with risk to develop metastases (rs2466287: OR $=0.43$, 95\% Cl 0.21-0.90; rs2672725: OR $=0.49,95 \% \mathrm{Cl}: 0.25-0.94 ;$ rs6879758: OR $=0.27$, $95 \% \mathrm{Cl}: 0.08-0.92$; rs6896163: $\mathrm{OR}=0.34,95 \% \mathrm{Cl}: 0.12-0.98)$. This finding supports the hypothesis that compounds acting through AHR may play a role in the invasive progression of TGCC, either directly or through modification of reproductive hormone action.

Keywords: aryl hydrocarbon receptor, aryl hydrocarbon receptor repressor, testicular germ cell cancers, genetic polymorphisms, genetic variation, association studies, metastasis, histology

\section{INTRODUCTION}

Testicular germ cell cancer (TGCC) represents the most-frequently diagnosed cancer in young men between 20 and 40 years of age. The rates vary considerably according to region and ethnicity, which suggests that both environmental and genetic factors contribute to TGCC. In Europe, a three- to fourfold increased incidence has been noted during the past 30-40 years, which suggests that an increased exposure to persistent environmental pollutants may play an important role.

Common persistent environmental pollutants include dioxins and polycyclic aromatic hydrocarbons, which exert their toxic and carcinogenic effects through the ligand-activated transcription factor aryl hydrocarbon receptor (AHR). In complex with its binding partner AHR nuclear translocator (ARNT), it mediates cellular responses to xenobiotic compounds. The AHR/ARNT heterodimer stimulates the expression of AHR repressor (AHRR), which provides a negative feedback regulation by competing with ARNT for binding to AHR (Mimura et al., 1999).

Testicular germ cell cancer derives from carcinoma in situ (CIS) cells, also known as intratubular germ-cell neoplasia unclassified (Skakkebaek et al., 1982; Oosterhuis and Looijenga, 2005), that are believed to arise from primordial germ cells that are blocked in differentiation. The initial malignant transformation of germ cells is thought to be caused by hormonal disturbances in the microenvironment of differentiating germ cells (Skakkebaek et al., 1987; Sharpe and Skakkebaek, 1993; Rajpert-De Meyts et al., 1998). An association of TGCC with maternal estrogen and androgen levels in early pregnancy has recently been reported, supporting this hypothesis (Holl et al., 2009). In addition to altering transcription of steroidogenic genes, such as cytochrome P450 enzymes, the 
AHR signaling pathway has been shown to interface with estrogen and androgen receptor signaling (Jana et al., 1999; Kizu et al., 2003; Safe and Wormke, 2003; Boverhof et al., 2006; Beischlag et al., 2008; Kollara and Brown, 2010). Additionally, AHR plays a significant role in tumor promotion and progression by deregulation of cellcell contact and inhibition of apoptosis (Mulero-Navarro et al., 2005; Diry et al., 2006; Carvajal-Gonzalez et al., 2009; Chopra et al., 2009; Dietrich and Kaina, 2010).

The risk of environment-related carcinogenesis depends not only on the magnitude of the exposure, but also on individual susceptibility to the pollutant. Therefore, we aimed to analyze the association between polymorphic variants of genes encoding AHR and AHRR and the risk as well as histological and clinical features of TGCC.

\section{MATERIALS AND METHODS}

The cohort consisted of TGCC patients from Sweden and Denmark, two neighboring Scandinavian countries, with populations sharing largely the same genetic background as both descended from a common ancestral population.

\section{SWEDISH TGCC PATIENTS}

All TGCC patients that were referred to the Department of Oncology, Skåne University Hospital, Lund, the Department of Oncology, Radiumhemmet or Södersjukhuset, Karolinska University Hospital, Stockholm since March 1996 and November 1998 until October 2006, respectively, were asked to participate in a study focusing on reproductive function. In total 460 patients were eligible for the study, of which 75 declined to participate and 45 were excluded due to linguistic problems, bilateral testicular cancer, physical handicap, or moving to another region. Seven patients were excluded due to compromising mental conditions, 10 were excluded due to contra-lateral testicular cancer diagnosed after inclusion and 3 died of progressive disease before blood samples were obtained. Among the 320 participants in the study on reproductive function, no DNA was available for 39. Additionally, 3 patients were excluded due to extra-gonadal germ cell cancer, leaving the total at 278. All patients gave their informed written consent and the study was approved by the Ethical Boards of Lund University and Karolinska Institute.

\section{DANISH TGCC PATIENTS}

In the period between 1999 and 2008, DNA was collected from approximately 300 TGCC patients on the occasion of semen banking prior to surgery or fertility assessment after treatment. One hundred samples were random selected for this study; the criterion for selection being sufficient DNA amount. In total, 11 patients were excluded because of mistaken diagnosis $(n=6)$, purely extragonadal tumor $(n=4)$, and in one case because the genetic SNP analysis failed. Among the remaining 89 patients, 5 presented with CIS only and were therefore not included in the analysis of distribution of seminomas (SE) versus non-seminomas (NSE). For six patients no information on stage was available.

\section{CONTROL SUBJECTS}

Control subjects were recruited in a study of reproductive function among Swedish military conscripts aged 18-20 years in the period 2000-2001 (Richthoff et al., 2002). As part of the investigation, scrotal palpation and ultrasound was performed in order to exclude testicular tumors or microcalcifications, which are indicative of an increased risk of CIS. Furthermore, they delivered one ejaculate for semen analysis as well as a blood sample for assessment of hormone levels. Among the 305 men that were eligible, 214 men with a Swedish mother were selected as control subjects (Table 1).

\section{GENOTYPING}

Genomic DNA was prepared from peripheral leukocytes using QIAamp DNA Maxi Kit (Qiagen, Germany). All samples were normalized to the same DNA concentration and the genotypes were determined using the Sequenom MassArray MALDI-TOF mass spectrometry. Eleven SNPs in the gene encoding aryl hydrocarbon receptor $(A H R)$ and 18 SNPs in the gene encoding aryl hydrocarbon receptor repressor $(A H R R)$ with a minor allele frequency $>0.05$ that were identified as haplotype-tagging SNPs were selected using dbSNP (available at: http://www.ncbi.nlm.nih.gov/SNP) and SNP assays were designed using MassArray Assay Design ver. 2 software (Sequenom Inc., USA). Primers were obtained from Metabion $\mathrm{GmbH}$ (Germany) and all reactions were run under the same conditions, except for the primer annealing temperature of the primary PCR. PCR reactions were performed in a total volume of $6 \mu \mathrm{L}$ containing $2.5 \mathrm{ng}$ template DNA, $1.25 \times$ Taq PCR buffer (Hotstar, Qiagen), $0.15 \mathrm{U}$ Taq polymerase (Hotstar, Qiagen), $3.5 \mathrm{nM} \mathrm{MgCl}_{2}, 0.5 \mathrm{mM}$ dNTP, and $100 \mathrm{nM}$ of each primer. Amplifications were performed using

Table 1 | Characteristics of controls and case patients.

\begin{tabular}{|c|c|c|c|}
\hline & Control & TGCC-SE & TGCC-DK \\
\hline & $n(\%)$ & $n(\%)$ & $n(\%)$ \\
\hline$n$ & 214 & 278 & 89 \\
\hline Age (year) & $18 \pm 0$ & $31 \pm 7$ & $31 \pm 8$ \\
\hline \multicolumn{4}{|l|}{ Histology } \\
\hline NSE & & $153(55.0)$ & $34(38.2)$ \\
\hline SE & & $125(45.0)$ & $50(56.2)$ \\
\hline CIS only & & & $5(5.6)$ \\
\hline \multicolumn{4}{|l|}{ Stage } \\
\hline Localized & & 200 (71.9) & $65(73.0)$ \\
\hline Metastasis & & $78(28.1)$ & $18(20.2)$ \\
\hline Unknown & & & $6(6.7)$ \\
\hline \multicolumn{4}{|c|}{ Family history of TGCC } \\
\hline Yes & $0(0)$ & $9(3.2)$ & $7(2.3)$ \\
\hline No & $214(100)$ & $250(90.3)$ & 77 (88.5) \\
\hline Unknown & & $19(6.5)$ & $5(9.2)$ \\
\hline \multicolumn{4}{|c|}{ History of cryptorchidism } \\
\hline Yes & $7(3.3)$ & $23(8.3)$ & $13(14.6)$ \\
\hline No & $207(96.7)$ & 247 (88.9) & $63(70.8)$ \\
\hline Unknown & & $8(2.9)$ & 13 (14.6) \\
\hline
\end{tabular}


GeneAmp 9700 machines with dual-384 heads as follows: $95^{\circ} \mathrm{C}$ for $15 \mathrm{~min}, 45$ cycles at $95^{\circ} \mathrm{C}$ for $20 \mathrm{~s}, 56^{\circ} \mathrm{C}, 60^{\circ} \mathrm{C}$, or $64^{\circ} \mathrm{C}$ for $30 \mathrm{~s}, 72^{\circ} \mathrm{C}$ for $60 \mathrm{~s}$, and finally $72^{\circ} \mathrm{C}$ for $3 \mathrm{~min}$. Dephosphorylation of unincorporated $\mathrm{dNTP}$ was achieved using shrimp alkaline phosphatase. Concentrations of individual homogenous MassEXTEND (hME) primers were adjusted to even out peak heights in the mass spectrum. The extension reactions were carried out by mixing the adjusted primer mix (containing approximately $1 \mu \mathrm{M}$ of each primer) with hME mix containing buffer and $50 \mu \mathrm{M}$ of each d/ddNTP mix and 1.25 U of Thermo Sequenase (Amersham Biosciences, Uppsala, Sweden). PCR amplification of hME reactions was performed as follows: $94^{\circ} \mathrm{C}$ for $2 \mathrm{~min}$ and 99 cycles at $94^{\circ} \mathrm{C}$ for $5 \mathrm{~s}, 52^{\circ} \mathrm{C}$ for $5 \mathrm{~s}$, and $72^{\circ} \mathrm{C}$ for $5 \mathrm{~s}$. The samples were then manually desalted by using $6 \mathrm{mg}$ of Clean Resin and a dimple plate and subsequently transferred to a 384-well SpectroCHIP using a nanodispenser. Randomly selected samples of each genotype were directly sequenced in order to validate the SNP assays.

\section{STATISTICAL ANALYSIS}

Single-nucleotide polymorphisms data was processed and analyzed using the web-based SNPator data analysis suite (MorcilloSuarez et al., 2008). Agreement with Hardy-Weinberg equilibrium was tested using a $\chi^{2}$ goodness-of-fit test. TGCC patients were divided in two groups depending on whether they were diagnosed with SE or NSE. Logistic regression association was used to calculate the odds ratio (OR) and 95\% confident interval for developing TGCC, for developing either SE or NSE, and for developing disseminated disease [defined by stages II, III, and IV according to the Royal Marsden Hospital staging classification (Husband and Koh, 2004), with stage I disease defined as tumor confined to the testis, with no evidence of metastases]. In the latter analysis histological subtype was included as a covariant in the logistic regression. Associations were considered statistically significant at $p<0.05$. Assuming a co-dominant additive model, we tested a linear trend of increasing effect in the different genotypes using linear-by-linear association $\chi^{2}$ statistics (SPSS ver. 21). Linkage disequilibrium (LD; i.e., non-random association of alleles) was assessed for each gene. The LD between identified SNPs was determined by pairwise comparisons of correlation coefficient between SNPs $(r)$ and the likelihood that recombination has occurred between SNPs $\left(D^{\prime}\right)$. Since we expected that the selected SNPs have a small contribution to TGCC and we regard our study to be exploratory rather than confirmatory, we have chosen to avoid correction for multiple testing. This may increase the risk of type 1 errors, but it prevents type 2 errors.

\section{RESULTS}

No significant deviations from Hardy-Weinberg equilibrium were detected for the SNPs included in the analysis.

We did not find a statistically significant association between the studied polymorphisms and the risk of TGCC.

For four SNPs in AHRR a significant allele association with the occurrence of disseminated disease was observed (Table 2). Patients with metastatic disease had significantly lower frequencies of the minor rs2466287 G, rs2672725 G, rs6879758 C, and rs6896163 $\mathrm{G}$ alleles compared to patients with localized disease
( 5 vs $10 \%, 6$ vs $11 \%, 2$ vs $5 \%$, and 2 vs $6 \%$, respectively), which were associated with $57,51,73$, and $66 \%$, reduced per allele OR for developing metastatic TGCC, respectively. Heterozygous carriers of AHRR variants rs6879758 and rs6896163 had a 74 and $67 \%$ reduced risk of developing metastatic TGCC, respectively. Due to very low frequencies, or even absence, of homozygous carriers of the $A H R R$ variants the OR could not be calculated for these groups of patients. However, trend analyses demonstrated significant associations for all four AHRR variants.

Polymorphisms in AHRR did not show a significant association with risk of TGCC or histological subtype, which was also the case for SNPs in AHR. Histological subtype and the occurrence of metastasic disease were not associated with SNPs in AHR. LD analysis demonstrated a high correlation between rs2466287 and rs2672725 as well as between rs6879758 and rs6896163 (Table 3).

When analyzed in the two populations individually, similar statistically significant ORs for the four SNPs were observed in the Swedish population as compared to the combined population. The associations in the Danish populations showed similar tendencies, although these did not reach statistical significance.

\section{DISCUSSION}

In this study we have analyzed associations between SNPs in genes encoding AHR and AHRR and the risk of developing TGCC, histological subtype, and the occurrence of metastasis. Whereas no associations were found with SNPs in AHR, four variants in AHRR associated significantly with the occurrence of metastatic disease.

Both AHR and its negative regulator AHRR are ligand-activated transcription factors that belong to the family of basic helix-loophelix Per-Arnt-Sim (bHLH-PAS) proteins. They are ubiquitously expressed in almost all human tissues, with levels particularly high in the testis (Burbach etal., 1992; Tsuchiya et al., 2003). $2,3,7,8$-Tetrachlorodibenzo- $p$-dioxin (TCDD) is the most wellcharacterized exogenous ligand of AHR and it is known for its anti-estrogenic properties such as inhibition of estradiol-induced uterine weight increase and decreased levels of estrogen and progesterone receptors in uterus of rat and mice (Safe, 1995).

Several epidemiological studies have shown that TCDD promotes cancer, and experiments in AHR-deficient mice have shown that AHR is essential for the tumor-promoting effects of TCDD (Andersson et al., 2002; McMillan and Bradfield, 2007). Conversely, transgenic mice with a constitutively active AHR spontaneously develop tumors, their weights of testis and ventral prostate are decreased and the epididymal sperm reserve is reduced (Brunnberg et al., 2011). Furthermore, AHRR, the negative regulator of AHR signaling, functions as a tumor suppressor in multiple human tumors (Zudaire et al., 2008; Li et al., 2012). Several studies have shown that the AHR activation also interferes with reproductive health. An increased incidence of TGCC has been observed in workers exposed to TCDD (Kogevinas et al., 1997) and dioxins have been reported to reduce sperm number, and to decrease accessory sex gland weight and anogenital distance in rats (Mably et al., 1992; Gray et al., 1995; Sommer et al., 1996; Faqi et al., 1998; Ohsako et al., 2002).

While SNPs in either AHR or AHRR did not associate with the risk of TGCC, it is interesting that an association was observed between AHRR and dissemination of TGCC, since AHR signaling 


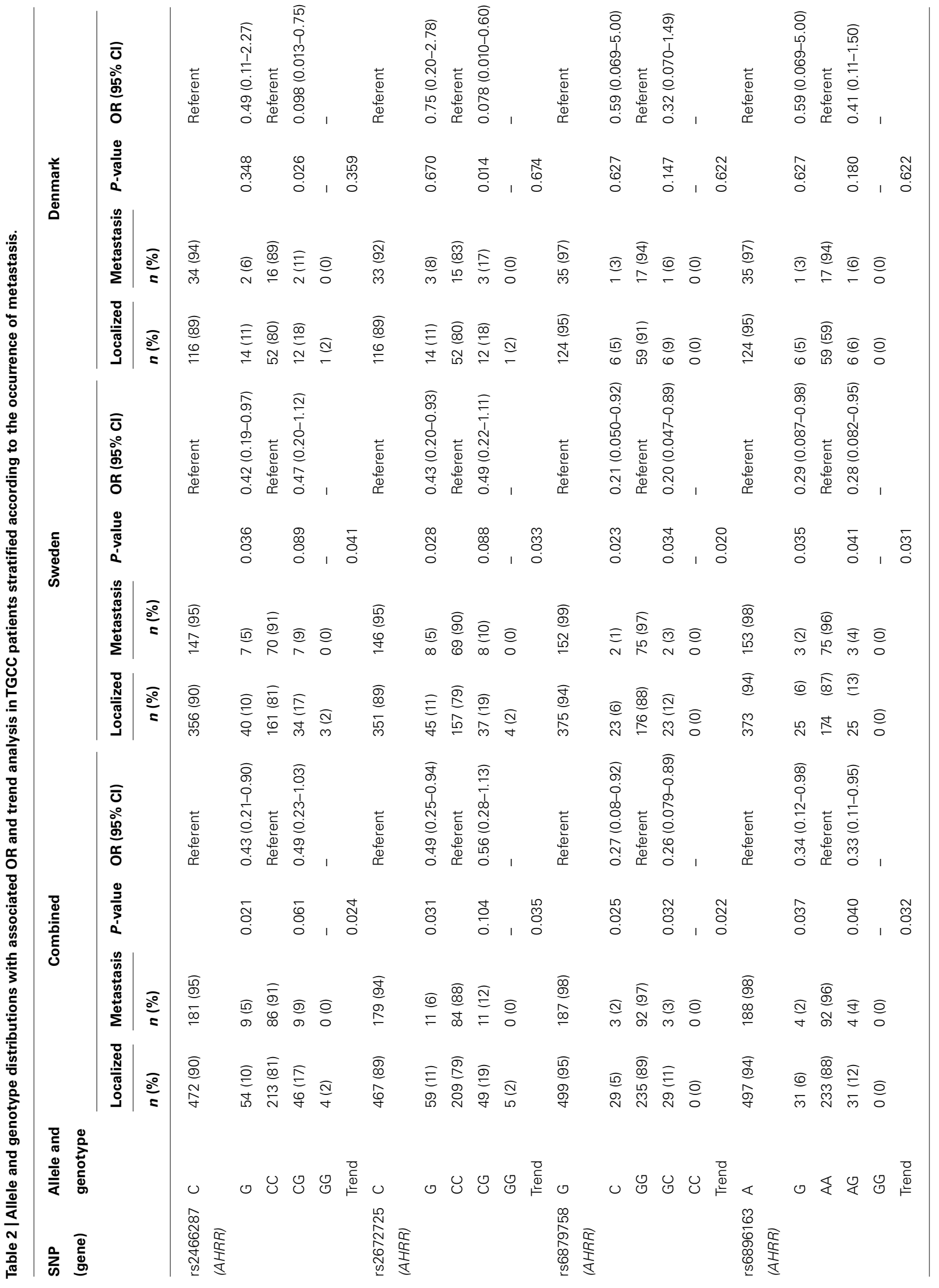


Table 3 | Linkage disequilibrium $\left(D^{\prime}\right)$ and correlation coefficients $(r)$ between SNPs in AHRR that associate with metastatic TGCC in the total population.

\begin{tabular}{|c|c|c|c|c|c|}
\hline \multicolumn{2}{|c|}{ rs2466287 } & \multicolumn{2}{|c|}{ rs2672725 } & \multicolumn{2}{|c|}{ rs6879758 } \\
\hline$D^{\prime}$ & $r$ & $D^{\prime}$ & $r$ & $D^{\prime}$ & $r$ \\
\hline
\end{tabular}

rs2466287

rs2672725 $0.978 \quad 0.909$

$\begin{array}{lllll}\text { rs6879758 } & 0.239 & 0.172 & 0.230 & 0.155\end{array}$

$\begin{array}{lllllll}\text { rs6896163 } & 0.195 & 0.142 & 0.186 & 0.132 & 0.999 & 0.948\end{array}$

is indeed known to contribute to the control of cell adhesion and migration (Carvajal-Gonzalez et al., 2009; Dietrich and Kaina, 2010). A potential role of AHR signaling in dissemination of TGCC is further supported by Koliopanos et al. (2002) who reported that AHR agonists decreased anchorage-independent pancreatic cancer cell growth.

Since testicular cancer rarely occurs before the onset of puberty, the malignant transformation of CIS cells may be associated with activation of the hypothalamic-pituitary-gonadal axis. An interaction between AHR signaling and steroid or gonadotropic hormones could therefore be an alternative mechanism underlying the association between AHRR polymorphisms and metastatic TGCC.

A strength of our study is the access to two independent TGCC populations. Although not all findings reached statistical significance in the Danish cohort when the countries were analyzed separately, most probably due to the limited number of cases in this group, the same trends with similar relative risks were

\section{REFERENCES}

Andersson, P., Mcguire, J., Rubio, C., Gradin, K., Whitelaw, M. L., Pettersson, S., et al. (2002). A constitutively active dioxin/aryl hydrocarbon receptor induces stomach tumors. Proc. Natl. Acad. Sci. U.S.A. 99, 9990-9995.

Beischlag, T. V., Luis Morales, J., Hollingshead, B. D., and Perdew, G. H. (2008). The aryl hydrocarbon receptor complex and the control of gene expression. Crit. Rev. Eukaryot. Gene Expr. 18, 207-250.

Boverhof, D. R., Kwekel, J. C., Humes, D. G., Burgoon, L. D., and Zacharewski, T. R. (2006). Dioxin induces an estrogen-like, estrogen receptor-dependent gene expression response in the murine uterus. Mol. Pharmacol. 69, 1599-1606.

Brunnberg, S., Andersson, P., Poellinger, L., and Hanberg, A. (2011). The constitutively active Ah receptor (CAAhR) mouse as a model for dioxin exposure - effects in reproductive organs. Chemosphere 85, 1701-1706.

Burbach, K. M., Poland, A., and Bradfield, C. A. (1992). Cloning of the Ahreceptor $\mathrm{cDNA}$ reveals a distinctive ligand-activated transcription factor. Proc. Natl. Acad. Sci. U.S.A. 89, 8185-8189.

Carvajal-Gonzalez, J. M., MuleroNavarro, S., Roman, A. C., Sauzeau, V., Merino, J. M., Bustelo, X. R., et al. (2009). The dioxin receptor regulates the constitutive expression of the vav3 proto-oncogene and modulates cell shape and adhesion. Mol. Biol. Cell 20, 17151727.

Chopra, M., Dharmarajan, A. M., Meiss, G., and Schrenk, D. (2009). Inhibition of UV-C light-induced apoptosis in liver cells by $2,3,7,8$ tetrachlorodibenzo- $p$-dioxin. Toxicol. Sci. 111, 49-63. The aryl hydrocarbon receptor (AhR) in the regulation of cell-cell contact and tumor growth. Carcinogenesis 31, 1319-1328.

Diry, M., Tomkiewicz, C., Koehle, C., Coumoul, X., Bock, K. W., Barouki, R., et al. (2006). Activation of the dioxin/aryl hydrocarbon receptor (AhR) modulates cell plasticity through a JNK-dependent mechanism. Oncogene 25, 5570-5574.
Dietrich, C., and Kaina, B. (2010).

found, which strengthens the relevance of our findings. We cannot exclude that a small fraction of the TGCC patients in our cohort were from non-Caucasian background. However, none of the allele frequencies of the analysed SNPs deviated from Hardy-Weinberg equilibrium, which indicates that either the non-Caucasian allele frequencies did not differ from those in the Caucasian population, or that non-Caucasians did not significantly contribute to the total cohort. The SNPs identified in this study are intronic polymorphisms, thus excluding structural changes in the proteins that these genes encode. Yet, polymorphisms in non-coding regions can still play an important role in the regulation of gene expression, e.g., by affecting mRNA stability, regulation by intronic micro RNAs, or potential splice sites. The identified SNPs could also be in $\mathrm{LD}$ with other genetic polymorphisms that are causally related to TGCC.

In summary, we have identified polymorphic variants in the gene encoding AHRR that associated with risk of disseminated TGCC. This supports our hypothesis that the AHR signaling pathway may affect the progression of TGCC, possibly by interfering with reproductive hormone actions.

\section{ACKNOWLEDGMENTS}

The authors would like to thank Marlene Dalgaard for help with collection of the patient data. This study was supported by grants from the Swedish Research Council (grants K2009-54X-21116-013 and K2009-54X-20095-04-3), the Swedish Cancer Society (CAN 2008/520 and 5148-B10-04PDF), the Research Fund and Cancer Research Fund of Malmö University Hospital, the Gunnar Nilsson Cancer Foundation, and King Gustaf V's Jubilee Fund for Cancer Research, Stockholm (grants 44052 and 74061) and the Danish Cancer Society (R40-A2127-11-S2).

Faqi, A. S., Dalsenter, P. R., Merker, H. J., and Chahoud, I. (1998). Reproductive toxicity and tissue concentrations of low doses of 2,3,7,8-tetrachlorodibenzo- $p$-dioxin in male offspring rats exposed throughout pregnancy and lactation. Toxicol. Appl. Pharmacol. 150, 383-392.

Gray, L. E. Jr., Kelce, W. R., Monosson, E., Ostby, J. S., and Birnbaum, L. S. (1995). Exposure to TCDD during development permanently alters reproductive function in male Long Evans rats and hamsters: reduced ejaculated and epididymal sperm numbers and sex accessory gland weights in offspring with normal androgenic status. Toxicol. Appl. Pharmacol. 131, 108-118.

Holl, K., Lundin, E., Surcel, H. M., Grankvist, K., Koskela, P., Dillner, J., et al. (2009). Endogenous steroid hormone levels in early pregnancy and risk of testicular cancer in the offspring: a nested case-referent study. Int. J. Cancer 124, 2923 2928.

Husband, J. E., and Koh, D. M. (2004). "Testicular germ cell tumours," in Imaging in Oncology, 2nd Edn, eds J. E. Husband and R. H. Reznek (London: Taylor and Francis), 401-427.

Jana, N. R., Sarkar, S., Ishizuka, M., Yonemoto, J., Tohyama, C., and Sone, H. (1999). Cross-talk between 2,3,7,8-tetrachlorodibenzop-dioxin and testosterone signal transduction pathways in $\mathrm{LNCaP}$ prostate cancer cells. Biochem. Biophys. Res. Commun. 256, 462-468.

Kizu, R., Okamura, K., Toriba, A., Kakishima, H., Mizokami, A., Burnstein, K. L., et al. (2003). A role of aryl hydrocarbon receptor in the antiandrogenic effects of polycyclic aromatic hydrocarbons in LNCaP human prostate carcinoma cells. Arch. Toxicol. 77, 335-343.

Kogevinas, M., Becher, H., Benn, T., Bertazzi, P. A., Boffetta, P., BuenoDe-Mesquita, H. B., et al. (1997). Cancer mortality in workers exposed to phenoxy herbicides, chlorophenols, and dioxins. An expanded and updated international cohort study. Am. J. Epidemiol. 145, 10611075. 
Koliopanos, A., Kleeff, J., Xiao, Y., Safe, S., Zimmermann, A., Buchler, M. W., et al. (2002). Increased arylhydrocarbon receptor expression offers a potential therapeutic target for pancreatic cancer. Oncogene 21, 6059-6070.

Kollara, A., and Brown, T. J. (2010). Four and a half LIM domain 2 alters the impact of aryl hydrocarbon receptor on androgen receptor transcriptional activity. J. Steroid Biochem. Mol. Biol. 118, 51-58.

Li, Y. F., Wang, D. D., Zhao, B. W., Wang, W., Yuan, S. Q., Huang, C. Y., et al. (2012). Poor prognosis of gastric adenocarcinoma with decreased expression of AHRR. PLoS ONE 7:e43555. doi: 10.1371/journal.pone.0043555

Mably, T. A., Bjerke, D. L., Moore, R. W., Gendron-Fitzpatrick, A., and Peterson, R. E. (1992). In utero and lactational exposure of male rats to 2,3,7,8-tetrachlorodibenzo- $p$ dioxin. 3. Effects on spermatogenesis and reproductive capability. Toxicol. Appl. Pharmacol. 114, 118-126.

McMillan, B. J., and Bradfield, C. A. (2007). The aryl hydrocarbon receptor sans xenobiotics: endogenous function in genetic model systems. Mol. Pharmacol. 72, 487-498.

Mimura, J., Ema, M., Sogawa, K., and Fujii-Kuriyama, Y. (1999). Identification of a novel mechanism of regulation of Ah (dioxin) receptor function. Genes Dev. 13, 20-25.

Morcillo-Suarez, C., Alegre, J., Sangros, R., Gazave, E., De Cid, R., Milne, R. et al. (2008). SNP analysis to results (SNPator): a web-based environment oriented to statistical genomics analyses upon SNP data. Bioinformatics 24, 1643-1644.

Mulero-Navarro, S., Pozo-Guisado, E., Perez-Mancera, P. A., AlvarezBarrientos, A., Catalina-Fernandez, I., Hernandez-Nieto, E., et al. (2005). Immortalized mouse mammary fibroblasts lacking dioxin receptor have impaired tumorigenicity in a subcutaneous mouse xenograft model. J. Biol. Chem. 280, 2873128741.

Ohsako, S., Miyabara, Y., Sakaue, M., Ishimura, R., Kakeyama, M., Izumi, H., et al. (2002). Developmental stage-specific effects of perinatal 2,3,7,8-tetrachlorodibenzop-dioxin exposure on reproductive organs of male rat offspring. Toxicol. Sci. 66, 283-292.

Oosterhuis, J. W., and Looijenga, L. H. (2005). Testicular germ-cell tumours in a broader perspective. Nat. Rev. Cancer 5, 210-222.

Rajpert-De Meyts, E., Jorgensen, N., Brondum-Nielsen, K., Muller, J., and Skakkebaek, N. E. (1998). Developmental arrest of germ cells in the pathogenesis of germ cell neoplasia. APMIS 106, 198-204.

Richthoff, J., Rylander, L., Hagmar, L., Malm, J., and Giwercman, A. (2002). Higher sperm counts in Southern Sweden compared with Denmark. Hum. Reprod. 17, 24682473.

Safe, S., and Wormke, M. (2003). Inhibitory aryl hydrocarbon receptor-estrogen receptor alpha cross-talk and mechanisms of action. Chem. Res. Toxicol. 16, 807-816.
Safe, S. H. (1995). Modulation of gene expression and endocrine response pathways by $2,3,7,8$ tetrachlorodibenzo-p-dioxin and related compounds. Pharmacol. Ther. 67, 247-281.

Sharpe, R. M., and Skakkebaek, N. E. (1993). Are oestrogens involved in falling sperm counts and disorders of the male reproductive tract? Lancet 341, 1392-1395.

Skakkebaek, N. E., Berthelsen, J. G., Giwercman, A., and Muller, J. (1987). Carcinoma-in-situ of the testis: possible origin from gonocytes and precursor of all types of germ cell tumours except spermatocytoma. Int. J. Androl. 10, 19-28.

Skakkebaek, N. E., Berthelsen, J. G., and Muller, J. (1982). Carcinoma-in-situ of the undescended testis. Urol. Clin. North Am. 9, 377-385.

Sommer, R. J., Ippolito, D. L., and Peterson, R. E. (1996). In utero and lactational exposure of the male Holtzman rat to 2,3,7,8-tetrachlorodibenzo-pdioxin: decreased epididymal and ejaculated sperm numbers without alterations in sperm transit rate. Toxicol. Appl. Pharmacol. 140, 146-153.

Tsuchiya, Y., Nakajima, M., Itoh, S., Iwanari, M., and Yokoi, T. (2003). Expression of aryl hydrocarbon receptor repressor in normal human tissues and inducibility by polycyclic aromatic hydrocarbons in human tumor-derived cell lines. Toxicol. Sci. 72, 253-259.

Zudaire, E., Cuesta, N., Murty, V., Woodson, K., Adams, L., Gonzalez, N., et al. (2008). The aryl hydrocarbon receptor repressor is a putative tumor suppressor gene in multiple human cancers. J. Clin. Invest. 118, 640-650.

Conflict of Interest Statement: The authors declare that the research was conducted in the absence of any commercial or financial relationships that could be construed as a potential conflict of interest.

Received: 14 November 2012; accepted: 07 January 2013; published online: 14 February 2013.

Citation: Brokken LJS, LundbergGiwercman Y, Rajpert-De Meyts E, Eberhard J, Ståhl O, Cohn-Cedermark $G$, Daugaard G, Arver S and Giwercman A (2013) Association between polymorphisms in the aryl hydrocarbon receptor repressor gene and disseminated testicular germ cell cancer. Front. Endocrin. 4:4. doi: 10.3389/fendo.2013.00004

This article was submitted to Frontiers in Cancer Endocrinology, a specialty of Frontiers in Endocrinology.

Copyright (C) 2013 Brokken, LundbergGiwercman, Rajpert-De Meyts, Eberhard, Ståhl, Cohn-Cedermark, Daugaard, Arver and Giwercman. This is an open-access article distributed under the terms of the Creative Commons Attribution License, which permits use, distribution and reproduction in other forums, provided the original authors and source are credited and subject to any copyright notices concerning any third-party graphics etc. 